\title{
ESSENTIAL OIL COMPOSITION OF FOUR ARTEMISIA SPECIES FROM ETHIOPIA
}

\author{
Nigist Asfaw $^{1 *}$ and Sebsebe Demissew ${ }^{2}$ \\ ${ }^{1}$ Department of Chemistry, College of Natural Sciences, Addis Ababa University, P.O. Box \\ 1176. Addis Ababa, Ethiopia \\ ${ }^{2}$ The National Herbarium, Department of Plant Biology \& Biodiversity Management, College of \\ Natural Sciences, Addis Ababa University, P.O. Box 3434, Addis Ababa, Ethiopia
}

(Received January 22, 2014; revised September 29, 2014)

\begin{abstract}
The essential oil composition of four Artemisia species, namely A. schimperi Sch. Bip. ex Engl. A. abyssinica Sch. Bip. ex A. Rich., A. afra Jacq. ex Willd., and A. absinthium L. (previously called A. rehan) from Ethiopia has been studied. The essential oil obtained from A. absinthium (seedling from Europe) grown in two places in Ethiopia (Addis Ababa and Butajira) was also analyzed for comparison. Morphological study on the leaves of A. absinthium L. from Ethiopia (previously called A. rehan) and A. absinthium (from Europe) was also conducted. The essential oils were obtained by hydrodistillation using a Clevenger apparatus and analyzed by capillary GC and GC/MS. Forty three compounds representing 76 to $94 \%$ of the oils were identified. The composition of the essential oils of A. schimperi, A. afra and A. abyssinica are mainly dominated by irregular monoterpenes: yogomi alcohol (13.5-37.6\%), artemisyl acetate (12.7-35.5\%), and artemisia ketone (2.3-13.2\%). The composition of the oil of A. absinthium (previously A. rehan) however, differs from the other three species in having camphor (21.2-28.3\%) and davanone (21.3-26.5\%) as major components. The composition of $A$. absinthum (Europe) was found to have $\beta$-thujone (42.3-66.4\%) and chamazulene (11.3-24.2\%) as major components. The study indicated that the composition of the essential oil of A. absinthium (previously A. rehan) is not only different from the other three species but also from A. absinthium from Europe and does not belong to any of the chemotypes described for the species in the literature. The morphological study on the leaves also showed that it differs from that of A. absinthium from Europe.
\end{abstract}

KEY WORDS: Artemisia schimperi, A. afra, A. abyssinica, A. absinthium, A. rehan, Asteraceae, Essential oil, Lyratyl isovalerate, Camphor, Davanone

\section{INTRODUCTION}

The genus Artemisia in the Family Asteraceae (Compositae) includes small herbs and shrubs, and is one of the largest with about 388 species with a worldwide distribution [1]. In Ethiopia the genus is represented by four species, namely A. schimperi Sch. Bip. ex Engl., A. abyssinica Sch. Bip. ex A. Rich., A. afra Jacq. ex Willd., and A. absinthium L. [1]. A. schimperi is a strongly aromatic annual to perennial herb endemic to Ethiopia. The fragrant leaves are important for their aromatic and medicinal properties. A. abyssinica, known by local names as "Aguppe", "Chyanchye", "Chikugn", and" Jukun" is an erect or semi-perennial herb. It grows wild and is also cultivated for its use in traditional medicine, as remedy for colds and heart troubles. A. afra which is known by local names as "Chirakot", "Ariti", "Chikugn", "Kappaanii" is used locally to relieve nasal congestion and headache. It is also used as fumigant. A. absinthium, known by local names as "Aguppe", "Arrittii" ("Ariti") and "Atran", is widely cultivated in Ethiopia for its pleasant aroma and medicinal properties in treating stomachache [2].

Numerous studies have been reported on the analysis of the essential oil compositions of Artemisia species [2-22]. In Afro-Asian countries, many species of Artemisia such as A. abyssinica Sch. Bip., A. herba-alba Asso., A. judaica L. and A. monosperma Del. are used in folk medicine as anthelmintics, antispasmodics, antirheumatics and antibacterial agents due to the presence of alkaloids, flavonoids, sterols, tannins, volatile oils and anthraquinones [7].

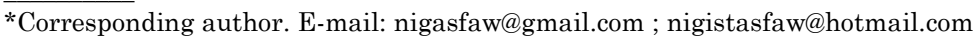


Powdered leaves of A. absinthium, A. biennis, A. frigida and A. ludoviciana have been applied externally in salves and washes by North American native people for treating sores and wounds and, internally to treat chest infections [12]. There are, however, a few reports on Artemisia species from Ethiopia [14-22].

In this work a comparative study of the essential oil composition of four Artemisia species from Ethiopia (A. abyssinica, A. schimperi, A. absinthium and A. afra) was carried out. A. rehan Chiov. that was known to be endemic to Ethiopia has been considered a synonym of $A$. absinthium [1]. Questions have been raised whether or not the taxon that was considered endemic falls within the variation of $A$. absinthium or could be recognized as a distinct taxon below the species. The composition of the essential oil of the taxon (previously known as $A$. rehan) from Ethiopia (Addis Ababa and Butajira) is compared with those reported in the literature for the same species and also with that of A. absinthium introduced from Europe and grown in the Department of Chemistry Garden of Addis Ababa University (AAU) and Butajira home garden. Morphological study on the leaf of the specimens were conducted and compared with the specimens in the Herbarium at the Natural History Museum in Copenhagen (C).

\section{Plant material}

\section{EXPERIMENTAL}

The plant materials A. abyssinica, A. afra, A. schimperi were collected from south eastern Ethiopia and they were all in full blooming stage. A. abyssinica (voucher specimen SD 6634) and A. afra (SD 6633); were collected from Gese, Dinshu Bale National Park [707'16.5'’N 39 ${ }^{\circ} 43$ '47.0' 'E] at $3050 \mathrm{~m}$ altitudes on 27/06/07; Artemisia schimperi (SD 6348), $31 \mathrm{~km}$ from Goba towards Dolo [0649'28.8'’N 3951'86.9''E] at $4000 \mathrm{~m}$ altitude on 04/09/04. A. absinthium, previously known as A. rehan (voucher specimen SD and NA 6911) was collected from a market in Addis Ababa on 10/12/10 and also collected from a cultivated plant in Butajira (SD and NA 6912) on 14/03/11. A absinthium introduced from Europe and grown in the Department of Chemistry Garden, AAU (Voucher specimen SD and NA 6907, collected on 03/11/2010), and cultivated in home garden in Butajira (Voucher specimen SD and NA 6992, collected on 24/09/11) and the specimens at the Herbarium at the Natural History Museum in Copenhagen $(\mathrm{C})$ were used to look at the variations in leaf morphology. The voucher specimens were authenticated by SD and deposited at the National Herbarium (ETH), Addis Ababa University, Ethiopia.

\section{Isolation and analysis}

The plant specimens for the chemical analysis were air-dried in a shade and the aerial parts were subjected to hydrodistillation for 3 hours using a Clevenger type apparatus. The oils were dried using anhydrous sodium sulfate and kept in a glass vial in the fridge for analysis.

The essential oil samples were analyzed by a DANI GC 1000 DPC Gas Chromatograph equipped with an ECTm-5 fused silica capillary column, with nitrogen as a carrier gas at a flow rate of $0.7 \mathrm{~mL} / \mathrm{min}$, and with a split ratio of 50 . The column temperature was programmed from $70{ }^{\circ} \mathrm{C}(5 \mathrm{~min})$ to $180{ }^{\circ} \mathrm{C}$ at $10{ }^{\circ} \mathrm{C} / \mathrm{min}$ to $240{ }^{\circ} \mathrm{C}(20 \mathrm{~min})$. An FID detector was used at a temperature of $260^{\circ} \mathrm{C}$ and the injection temperature was $210^{\circ} \mathrm{C}$.

The GC-MS analysis of the oils was performed using a Varian gas chromatograph equipped with DB-1 (30 m, $0.25 \mathrm{~mm}$ i.d., 0.25 um film thickness) fused silica capillary columns directly coupled to Quadrupole MS, which was operated in EI mode $(70 \mathrm{eV})$. Helium was the carrier gas at a flow rate of $1.1 \mathrm{~mL} / \mathrm{min}$. The injector temperature was $250{ }^{\circ} \mathrm{C}$, and the oven temperature was programmed from $50{ }^{\circ} \mathrm{C}$ to $250{ }^{\circ} \mathrm{C}$ at $5{ }^{\circ} \mathrm{C} / \mathrm{min}$, and finally held isothermal at $250{ }^{\circ} \mathrm{C}$ for 15 min. The area percentage was obtained electronically from the GC-FID response without the use of an internal standard or correction factors. 


\section{Identification of compounds}

The retention indices (RIs) for all of the compounds were determined by co-injection of the sample with a mixture of the homologous series of C8-C25 n-alkanes. Identification of components was based on comparison of their mass spectra (MS) with those of NIST MS search 2.0 and Wiley 275 libraries and with those described by Adams [23].

\section{RESULTS AND DISCUSSION}

The essential oils were obtained by hydrodistillation using a Clevenger apparatus and analyzed by capillary GC and GC/MS. Identification of components was based on comparison of their mass spectra (MS) with those of NIST and Wiley 275 libraries and with those described by Adams [23]. The essential oil yields were found to be $1.2 \%(\mathrm{v} / \mathrm{w})$ for $A$. schimperi, $1.4 \%$ for $A$. abyssinica, $1.8 \%$ for $A$. afra, and $0.2 \%$ for A. absinthium (A. rehan). Forty four compounds representing 76 to $94 \%$ of the oils were identified (Table 1 ).

The essential oil of A. schimperi which is endemic to Ethiopia was found to have yogomi alcohol (19.6\%), artemisyl acetate (12.7\%), lyratyl isovalerate $(10.5 \%)$ and artemisia alcohol $(9.2 \%)$ as major components. Previous work on the plant revealed the identification of four compounds, namely 1,5-octadiene-3-hydroxy-3-methyl-7-one, artemisyl acetate, lyratyl acetate and quercetin 3,3',4'-trimethyl ether [17]. Artemisyl acetate was also isolated from the plant and identified by NMR before [18].

The essential oil of A. abyssinica comprised of yogomi alcohol (37.6\%), artemisyl acetate $(22.4 \%)$ and artemisia alcohol $(8.8 \%)$ as the major components. These compounds were reported before in the plant from other parts of Ethiopia with some quantitative difference [20, 21]. However, Burits et al. [15] reported 4-hydroxycyclohexanemethanol (21.3\%) and $\alpha$ terpinolene $(9.2 \%)$ to be the main components of the essential oil of the plant purchased from the market in Addis Ababa. Nibret and Wink [19] identified tentatively octa-3,5-diene-2,7dione,4,5-dihydroxy (54.95\%), 1-tetracosanol (8.02\%), and butanoic acid, 6-ethyl-3octyl-ester $(6.25 \%)$ as major compounds of the dichloromethane extract. These compounds were not detected in the oil in the present work.

The essential oil of A. Afra was found to have artemisyl acetate (35.5\%), yogomi alcohol $(13.5 \%)$, artemesia ketone $(13.2 \%)$ as major compounds. Previous work on the plant indicated artemisyl acetate (24.4-32.1\%) and yogomi alcohol (21.6-26.8\%) as the major compounds [22]. Nibret and Wink [19] tentatively identified epoxylinalool (29.10\%) and dihydrocostunolide $(22.14 \%)$ as the major compounds of the dichloromethane extract of $A$. afra. The main compounds of the essential oil of $A$. afra were camphor $(26.8 \%)$, davanone (16.6\%), bornyl acetate (3.8\%), 4-terpineol (3.6\%) and chamazulene (3.2\%), according to Burits et al. [15]. The composition reported by Burits et al. [15] for the oil has similar composition with that of $A$. absinthium (synonym A. rehan). It is a possibility that sample was misidentified for A. rehan [Personal communication].

The essential oil composition of A. absinthium (previously A. rehan) samples was dominated by camphor (21.2-28.3\%) and davanone (21.3-26.5\%) as major components (Table 1). Abegaz et al. [14] and ALNAP [21] also reported davanone and camphor as major components for the plant. Nibret and Wink [19] reported camphor (38.73\%), ethyl cinnamte $(10.62 \%)$, and davanone $(6.57 \%)$ as major components of the dichloromethane extract of $A$. absinthium (A. rehan).

The essential oil samples obtained from A. absinthium introduced from Europe and which was grown in the garden of Department of Chemistry, Addis Ababa University (AAU) and in Butajira home garden were also analysed. The major compounds of the essential oils were found to be $\beta$-thujone (42.3-66.4\%) and chamazulene (11.3-24.2\%), which is in agreement with those reported for the species in the literature, despite the different growing environment in Ethiopia. 
The essential oil of A. absinthium originating from different countries has been the subject of previous investigations and different chemotypes were reported in literature $[3-8,12]$. Four chemotypes were identified to be characteristic of $A$. absinthium grown in Europe: sabinene and myrcene rich oil, $\alpha$ - and $\beta$-thujone rich oil, epoxyocimene rich oil, and $(E)$-sabinyl acetate rich oil. Some mixed chemotypes were also found [3].

Table 1. Chemical composition of the essential oils of Artemisia species.

\begin{tabular}{|c|c|c|c|c|c|c|c|c|}
\hline \multirow[t]{2}{*}{ Compounds } & \multirow[t]{2}{*}{ RI } & \multirow[t]{2}{*}{ A. afra } & \multirow[t]{2}{*}{ A. schimperi } & \multirow[t]{2}{*}{ A. abyssinica } & \multicolumn{2}{|c|}{ A. absinthium (A. rehan) } & \multicolumn{2}{|c|}{ A. absinthium } \\
\hline & & & & & AA Market & $\begin{array}{l}\text { Butajira } \\
\text { garden }\end{array}$ & $\begin{array}{l}\text { Chem. } \\
\text { garden }\end{array}$ & $\begin{array}{c}\text { Butajira } \\
\text { garden }\end{array}$ \\
\hline Santolina triene & 903 & 0.4 & 0.5 & 0.2 & 0.3 & 1.2 & 0.1 & 0.4 \\
\hline$\alpha$-Pinene & 917 & 0.3 & 5.0 & 2.1 & 0.9 & 1.3 & 0.4 & 1.3 \\
\hline Camphene & 956 & 0.4 & 0.3 & 0.7 & 1.1 & 0.7 & 0.1 & 0.2 \\
\hline Sabinene & 973 & 1.6 & 1.3 & 4.1 & 1.4 & 2.2 & 0.1 & 0.1 \\
\hline$\beta$-Pinene & 986 & 0.1 & 0.2 & 0.2 & 0.5 & 0.8 & 1.0 & 3.0 \\
\hline Yogomi alcohol & 1000 & 13.5 & 19.6 & 37.6 & - & - & - & - \\
\hline Limonene & 1029 & 1.9 & 6.6 & 0.8 & 0.4 & 0.5 & 0.2 & 0.1 \\
\hline$\beta$-Phellandrene & 1032 & 0.7 & 0.3 & 0.8 & 0.9 & 0.5 & 0.2 & 0.6 \\
\hline 1,8-Cineole & 1037 & 3.5 & 1.0 & 0.9 & 1.6 & 0.9 & 0.1 & 0.1 \\
\hline$\gamma$-Terpinene & 1055 & - & - & - & - & - & 0.4 & 0.6 \\
\hline Artemisia ketone & 1063 & 13.2 & 2.3 & 1.0 & - & - & - & - \\
\hline Artemisia alcohol & 1072 & 1.6 & 9.2 & 8.8 & - & - & - & - \\
\hline Linalool & 1085 & 2.8 & 0.8 & 0.6 & 3.1 & 3.0 & - & - \\
\hline$\alpha$-Thujone & 1104 & - & - & - & - & - & 1.0 & 1.4 \\
\hline$\beta$-Thujone & 1115 & - & - & - & - & - & 42.3 & 66.4 \\
\hline Camphor & 1150 & 1.0 & 0.3 & 0.4 & 21.2 & 28.3 & - & - \\
\hline Borneol & 1170 & - & - & - & 0.4 & 0.5 & - & - \\
\hline Artemisyl acetate & 1175 & 35.5 & 12.7 & 22.4 & - & - & - & - \\
\hline Terpinen-4-ol & 1180 & - & 0.5 & 1.4 & 2.5 & 1.7 & 1.3 & 1.5 \\
\hline$\alpha$-Terpineol & 1197 & 0.4 & 0.8 & 0.3 & 0.3 & 0.5 & 0.6 & 0.1 \\
\hline Geraniol & 1259 & 5.4 & 6.0 & 0.5 & - & - & - & - \\
\hline Lyratyl isovalerate & 1278 & - & 10.5 & - & - & - & - & - \\
\hline Bornyl acetate & 1307 & 8.0 & 0.6 & 0.6 & 2.4 & 2.0 & 0.4 & 0.1 \\
\hline Methyl cinnamate $(Z)$ & 1317 & 0.6 & 0.5 & 0.1 & 0.4 & 0.4 & - & - \\
\hline Neryl acetate & 1326 & 1.1 & 1.9 & 0.6 & - & - & 0.4 & 0.1 \\
\hline 2-Phenylpropanoate & 1353 & - & 1.0 & - & 0.4 & 0.4 & - & - \\
\hline Ethyl cinnamate $(Z)$ & 1380 & - & - & - & 0.9 & 1.2 & - & - \\
\hline Methyl cinnamate (E) & 1384 & - & 0.5 & - & 0.3 & 0.2 & - & - \\
\hline \begin{tabular}{|l|} 
Methyl eugenol \\
\end{tabular} & 1386 & 0.1 & - & - & 0.4 & 0.3 & - & - \\
\hline$\beta$-Caryophyllene & 1389 & - & - & - & 2.2 & 0.3 & 2.1 & 1.1 \\
\hline 2-Phenylethylbutanoate & 1404 & - & 0.3 & - & 0.5 & 0.1 & - & - \\
\hline Ethyl cinnamate $(\mathrm{E})$ & 1472 & - & - & - & 9.9 & 4.9 & - & - \\
\hline \begin{tabular}{|l|} 
Nerolidol \\
\end{tabular} & 1512 & 0.1 & 1.8 & 3.1 & 0.2 & 0.1 & - & - \\
\hline Davanone isomer & 1564 & - & - & - & 0.7 & 0.3 & - & - \\
\hline \begin{tabular}{|l|} 
Cubenol \\
\end{tabular} & 1568 & - & 0.7 & - & - & - & - & - \\
\hline \begin{tabular}{|l|} 
Davanone B \\
\end{tabular} & 1569 & - & - & - & 2.9 & 4.3 & - & - \\
\hline \begin{tabular}{|l|} 
Spathulenol \\
\end{tabular} & 1591 & 0.9 & - & - & - & - & - & - \\
\hline Davanone & 1593 & - & - & - & 21.3 & 26.5 & - & - \\
\hline$\alpha$-Selinene & 1621 & - & 0.5 & - & 0.8 & 0.3 & 0.6 & 0.2 \\
\hline$\beta$-Eudesmol & 1672 & - & - & 0.2 & 0.5 & 0.3 & - & - \\
\hline Chamazulene & 1731 & - & - & - & 3.1 & 4.3 & 24.2 & 11.3 \\
\hline Edusema-3,5,11-triene & 1791 & 0.5 & 0.6 & 1.2 & 0.5 & 0.8 & - & - \\
\hline Total identified & & 93.6 & 86.4 & 89.1 & 82.2 & 89.0 & 75.5 & 88.6 \\
\hline
\end{tabular}


The essential oil composition of A. absinthium (previously A. rehan) from Ethiopia is different from that of $A$. absinthium from Europe that was grown in Ethiopia. It is noteworthy that the Ethiopian A. absinthum (previously A. rehan) is also different in composition and does not belong to any of the chemotypes described for the species so far.

Morphological study on the leaves of specimen of A. absinthium (previously A. rehan) from Ethiopia indicated that the leaves are less dissected; final segments of leaves are oblanceolate to obovate and wider at apex. In contrast, the leaves of specimens of A. absinthium grown in Addis Ababa and Butajira, Ethiopia with seedlings from Europe and those at Copenhagen Herbarium (C) have more dissected leaves; the final segments are lanceolate to linear and acute at the apex (Figure 1). It appears specimens commonly cultivated in Ethiopia (known previously as $A$. rehan) have different chemical composition and subtle differences in leaf morphology compared with those specimens growing in the Garden of Department of Chemistry, AAU, Butajira home garden, and specimens at $\mathrm{C}$.

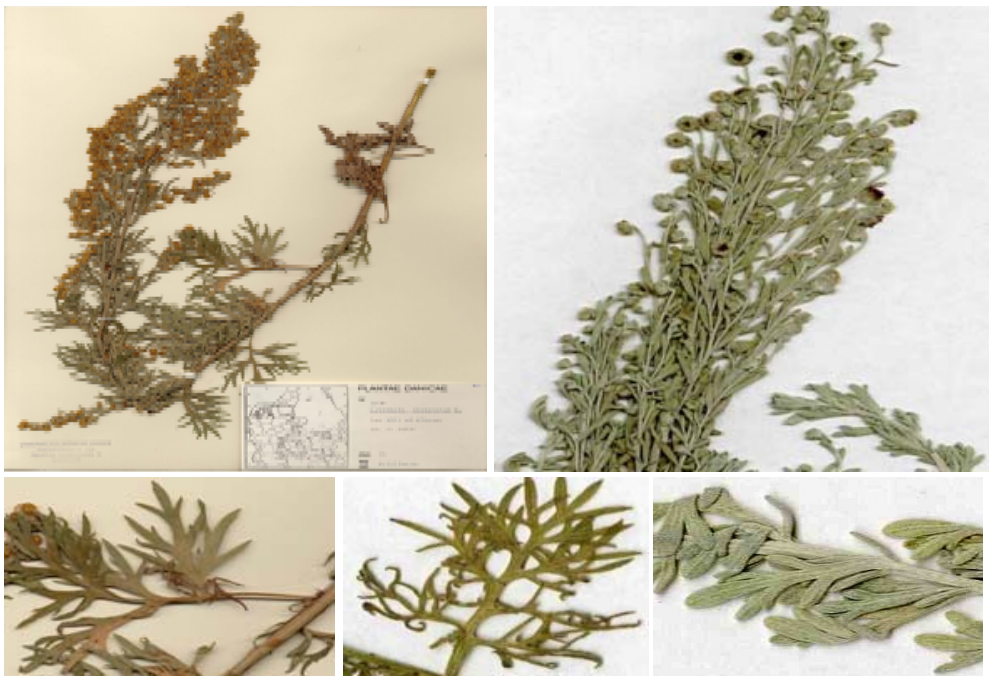

Figure 1. Artemisia absinthium (syn. A. rehan). Top left - Escaped or naturalised specimen, Vollesen 35, collected from low dunes of Albuen (the "Elbow"), Lolland, Denmark, and kept at C. Bottom left - Magnified leaf segment of the same specimen. Bottom centre - Magnified leaf segment of the plant sample of European origin and grown at the Department of Chemistry Garden in AAU (SD \& NA 6907). Top right - Cultivated plant sample of Ethiopian origin from Butajira, Ethiopia (SD \& NA 6912). Bottom right - magnified leaf segment of the same specimen.

The present comparative study indicated that the chemical composition of the essential oils of A. schimperi, A. afra and A. abyssinica are mainly dominated by irregular monoterpenes; yogomi alcohol, artemisyl acetate, artemisia ketone and artemisia alcohol. A. absinthium (previously A. rehan) oil's composition is however, different from the other three species having camphor and davanone as major components. The chemical composition of the species from Ethiopia is also different from those of $A$. absinthum of European origin.

Morphological studies on the leaves of A. absinthium (previously A. rehan) show that there are subtle differences between the Ethiopian specimens of the species and specimens of $A$. absinthum from Europe. This variation in addition to the differences in chemical composition warrant further taxonomic revision of the species throughout its range of distribution in order to 
ascertain whether A. absinthium is a single variable species or the Ethiopian taxon deserve a rank below the species or a resurrection at a species level.

\section{ACKNOWLEDGEMENTS}

We would like to acknowledge the support from both the National Herbarium (ETH), Addis Ababa University, the Herbarrium (C), Natural History Museum, University of Copenhagen and Prof. Ermias Dagne, Department of Chemistry, AAU in availing the A. absinthium specimen for the study. We are thankful to Dr. Mick Cooper, School of Chemistry, University of Nottingham for recording GC/MS of the oils. Financial support from DFID, the British Council -DeLPHE and Science Faculty, AAU is gratefully acknowledged.

\section{REFERENCES}

1. Tadesse, M. Asteraceae (Compositae) in Flora of Ethiopia and Eritrea, Hedberg, I.; Friis, I.; Edwards, S. (Eds.), Volume 4, Part 2, The National Herbarium, Addis Ababa University, Addis Ababa, Ethiopia and Uppsala, Sweden; 2004; 222.

2. Asfaw, N.; Demissew, S. Aromatic Plants of Ethiopia, Shama Books: Addis Ababa, Ethiopia; 2009; pp71-76.

3. Orav, A.; Raalb,A.; Arak, E.; Müürisepp, M.; Kailas, T. Proc. Estonian Acad. Sci. Chem. 2006, 55, 155 .

4. Blagojevicä, P.; Radulovicä, N.; Palicä, R.; Stojanovicä, A. J. Agric. Food Chem. 2006, 54, 4780.

5. Judpentienë, A. and Mockutë, D. Chemija 2004, 15, 64.

6. Rezaeinodehi, A.; Khangholi, S. Pak. J. Biol. Sci. 2008, 11, 946.

7. Adam, S.E.I.; AI-Qarawi, A.A.; Elhag, E.A. Lab. Anim. 2000, 34, 307.

8. Kordali, S.; Kotan, R.; Mavi, A.; Cakir, A.; Ala, A.; Yildirim, A. J. Agric. Food Chem. 2005, 53, 9452 .

9. Salido, S.; Valenzuela, L.R.; Altarejos, J.; Nogueras, M. ;Sanchez, A.; Cano, E. Biochem. Syst. Ecol. J. 2004, 32, 265.

10. Sefidkon, F.; Jalili, A.; Mirhaji, T. Flavour Fragr. J. 2002, 17, 150.

11. Segal, R.; Breuer, A.; Feuerstein, I. Phytochemistry 1980, 19, 2761.

12. Lopes-Lutz, D.; Alviano, D.S.; Alviano, C.S.; Kolodziejczyk, P.P. Phytochemistry 2008, 69, 1732.

13. Mohsen H.; Ali, F. Molecules 2009, 14, 1585.

14. Abegaz, B.; Yohannes, P.G. Phytochemistry 1982, 21, 1791.

15. Burits, M.; Asres, K.; Bucar, F. Phytother. Res. 2001, 15, 103.

16. Asfaw, N.; Licence, P.; Novitskii, A.A.; Poliakoff, M. Green Chem. 2005, 7, 352.

17. Abegaz, B.M.; Herz, W. Phytochemistry 1991, 30, 1011.

18. Tesfaye, B. Chemical investigation on the essential oil of A. schimperi, M.Sc. Graduate Project, Department of Chemistry, Addis Ababa University, Ethiopia, 2007.

19. Nibret, E.; Wink, M. Phytomedicine 2010, 17, 369.

20. Tariku, Y.; Hymete, A.; Hailu, A.; Rohloff, J. Chem. Biodivers. 2010, 7, 1009.

21. ALNAP, ICS-UNIDO Medicinal and Aromatic Plants Website. Available at: http://portal.ics.trieste.it/MAPs/EssentialOils_Oil.aspx? Accessed on April 14, 2004.

22. Worku, T.; Rubiolo, P. J. Essent. Oil Res. 1996, 8, 355.

23. Adams, R.P. Identification of Essential Oil Components by Gas Chromatography/Mass Spectrometry, Allured Publishing Corporation: Carol Stream, IL; 2007. 